\title{
Water Management Options for Rice Cultivation in a Temperate Area: A Multi-Objective Model to Explore Economic and Water Saving Results
}

\author{
Federica Monaco ${ }^{1, *}$, Guido Sali ${ }^{1}$, Manel Ben Hassen ${ }^{1}$, Arianna Facchi ${ }^{1}$, Marco Romani ${ }^{2}$ \\ and Giampiero Valè 3,4 \\ 1 Department of Agricultural and Environmental Sciences, University of Milan, via G. Celoria 2, Milan 20133, \\ Italy; guido.sali@unimi.it (G.S.); manel.benhassen@unimi.it (M.B.H.); arianna.facchi@unimi.it (A.F.) \\ 2 Rice Research Centre, Ente Nazionale Risi, Strada per Ceretto 4, Castello d'Agogna (PV) 27030, Italy; \\ m.romani@enterisi.it \\ 3 CREA-Council for Agricultural Research and Economics, Rice Research Unit, S.S. 11 per Torino km 2,5, \\ Vercelli 13100, Italy; giampiero.vale@crea.gov.it \\ 4 CREA-Council for Agricultural Research and Economics, Genomics Research Centre, via S. Protaso 302, \\ Fiorenzuola d'Arda (PC) 29017, Italy \\ * Correspondence: federica.monaco@unimi.it; Tel.: +39-02-5031-6466
}

Academic Editors: Giacomo Zanni, Davide Viaggi and Meri Raggi

Received: 30 May 2016; Accepted: 1 August 2016; Published: 8 August 2016

\begin{abstract}
Due to the changing climatic and environmental conditions, modifications in agricultural and water policies have been made, and irrigated agriculture has to face the challenge of making a rational and optimal use of the water resource effectively available. This urges rice farming, strongly and traditionally linked to water, to change the modalities for the use of the resource. If on one hand water saving techniques should be preferred, a different water management in paddy fields may lead to lower yields and higher production costs, with consequent repercussions on farm incomes. The paper recognizes the disagreement between environmental and economic concerns and aims at contributing to the discussion about how to reconcile them by adopting alternative irrigation strategies. From this perspective, a multi-objective linear optimization model is used to explore the trade-offs between conflicting objectives in a rice-growing area in Northern Italy. The model returns the optimal allocation of land subject to three different irrigation strategies, as those previously performed in experimental fields; in addition, a scenario analysis is run to simulate reduced resource availability. Results demonstrate the key role of prioritizing one objective over the other, while introducing cultivars more suitable for dry cultivation enables enlarging the frontier of optimal solutions.
\end{abstract}

Keywords: irrigation water; water saving; rice-cultivation; Italy; multi-objective optimization models; linear programming

\section{Introduction}

Rice is the second most important cereal and staple food in the world. Despite the fact that the majority comes from Asian countries, a significant extent of intended agricultural areas can also be found in the Mediterranean basin and in temperate Europe. Italy, with around 227,300 ha of rice land [1], is the European leading producer. In the western Po Valley the rice-growing district across Lombardy and Piedmont regions ensures $90 \%$ of the national production. Here, rice farming is currently facing manifold constraints [2] that limit the possibility in getting adequate productive and economic results. 
The main critical issue affecting regional rice-farming concerns water availability. Even in irrigated agriculture, for which water resources have not been traditionally a limiting factor, we must recognize that things are changing. The effects of climate change $[3,4]$ are in fact strongly affecting the amount of water available for agriculture [5,6]. Hot spots of water scarcity have been observed in many countries [7], whilst in several European areas a further raise is expected in the next decades [8]. According to APAT, the level of the Po River, which water are diverted to irrigate the largest part of Italian rice-fields, has fallen by $20 \%-25 \%$ since the last 30 years, whilst a further lengthening of the dry season and the increase of water stress are expected as well [9]. At the same time, a different distribution of available water over spring and summer may not always meet crop water requirements [10]. The competition for the resource amongst different sectors [11] and purposes [12] thus calls for integrating water requirements with availability.

On the other hand, the amount of water supplied tends to proportionally affect agricultural yields [13], with consequent repercussions on revenues and economic results of rice-growing farms, especially if small-sized [14]. Added to this, are the production costs of rice in Western Europe, which are generally much higher than both in most Asian countries and in the USA. [15]; following the marked increase in the price of fossil energy, in recent years they have undergone a further significant augmentation. As a further concern, rice-cultivation, being traditionally and strongly linked to water resource, is profoundly related to water policy. In first instance, water supply cost is a key element affecting total production costs. In general terms, irrigation water tariffs are much lower than those regulatory framework calls for (e.g., the Water Framework Directive); it is then reasonable that in an increase in the cost of water supply shall occur. Thereafter, farmers could be in the condition of managing less water at a higher cost, with possible negative consequences on their own incomes.

In addition, rice farming may be further threatened by different regime of CAP payments following the latest CAP reform (CAP 2014). A higher uncertainty in the amount of financial supports drives rice growers adopting strategies to exploit higher margins and counteract possible diminutions in subsidies.

These changed conditions are pushing the rice sector to seek new cultivation modalities and systems, which make a more rational and sustainable use of the resource. A large variety of options can be undertaken at the farm-level to (i) counteract water scarcity; (ii) adapt to the effective water availability and (iii) get adequate productive and economic returns. From this perspective, the issue of water saving is being paid much attention. In irrigated agriculture the manifold solutions that can be adopted range from a crop mix change, to the cultivation of less water-demanding crops, the reduction of irrigated farmland [16], the use of additional water sources $[17,18]$ to mitigate shortages from collective supply, the adoption of different irrigation systems [19]. In rice farming, the water problem is particularly addressed through either the cultivation of new rice varieties with improved traits, or the adoption of more efficient water management strategies. In the former case, valid options include the amelioration of crops [20] with selected varieties more resistant to water stress or more suitable for discontinuous irrigation, the adoption of hybrid rice cultivation [21], the introduction of short-cycle and high yielding cultivars. On the other hand, alternative water management options plays a central role. In European countries, more often, rice-fields are submerged immediately after tillage operations, seeds broadcasted in flooded fields and the crop maintained continuously submerged; this conventional technique makes water requirements of rice far higher than any other cereal [22]. Different irrigation systems, e.g., sprinkler [23], drip [24] or flush irrigation [25] are opportunities to lower the massive amounts of water associated with traditional rice farming, thanks to higher irrigation efficiency. Water saving cultures for rice also include the possibility to make a different use of water, which contributes in reducing outflows (i.e., leakages and percolation). Such techniques have been spreading worldwide and in temperate rice systems as well. In the Po Valley, both site-specific conditions and water availability levels determine multiple versions of alternative irrigation strategies $[10,26]$. In general terms, two are the main typologies that can be distinguished, namely (i) dry seeding and delayed flooding, which implies that rice is planted in dry soil and generally 
managed as a dry crop until the tillering stage; after then, the ponding water depth is maintained until the final drying, except for drying periods needed to apply fertilizers; and (ii) dry seeding and intermittent irrigation, i.e., aerobic rice [27]. It is a particular form of the previous strategy, operated especially in areas close to urban settlements and in presence of water scarcity. Rice is compared to other irrigated cereals, typically maize, with border irrigation interventions practiced every 7-15 days.

If on one hand, such strategies are recognized as water saving techniques, scarce direct indications about their economic implications are provided through out dedicated literature. The adoption of such alternative irrigation options is likely coupled with reduced productive performances [28] and to additional labor costs [10,29], given the enhanced presence of weeds [30]. More research is needed; this can provide sets of data to be used for quantifying the economics of rice production, to finally quantify the trade-offs between economic and environmental concerns.

\section{Addressing Conflicting Objectives in Irrigated Agriculture: A Brief Review}

Limited resources are more often to be managed in presence of conflicting objectives. Few are, however, the studies concerning this topic in irrigated agriculture. Despite this, they mostly recognize a disagreement between water saving and economic results, as evident by methodological approaches adopted to rank the most feasible alternatives or select their best allocations.

A first approach refers to multi-criteria analysis. It is particularly useful when participatory processes are carried out, with quantitative and qualitative information, as long as users' preferences are to be taken into account. For each proposed alternative, the method allows the calculation of a global utility value, which represents the integrative score based on the prioritization schemes related to one of the objectives or a balanced situation between them.

The methodology was performed to compare different irrigation systems scenarios for a same crop, namely maize in a Mediterranean area [19] and cotton in a semi-arid region [31,32], taking into account water saving and economic benefits as the main concerns. In the work of García de Jalon et al. [12], MCA served for evaluating adaptation measures to water scarcity in an area of southern Spain, where rice farming and protected wetlands are closely linked. In this case, authors input results from MCA to an optimization model, aimed at maximizing global utility and land-use diversification, recognized this latter as a relevant adaptation strategy.

Multi-objective problems are well suited to address trade-offs and synergies between conflicting objectives [33]. In applying them to irrigated agriculture, the best allocation of water and land resources is the main goal pursued. From this perspective, Latinopoulos [34] formulated a multi-criteria decision-making model for irrigated agriculture in a rural area of Greece. Based on multi-objective programming, it was aimed at simultaneously optimizing five objectives, related to the socio-economic and environmental spheres. A further optimization was implemented to allocate irrigation water in a Japanese rice paddy area with water saving practices [13]. The authors applied it to a hypothetical irrigation network considered representative for the region; objectives functions defined referred to the increase of profit (i.e., maximize total yield and water-saving costs) and water saving (i.e., maximize equity of water allocation and safety of water supply). A very similar model was proposed for a Chinese rice-growing area [35]. Still considering production and saving of agricultural water, it was applied to a hypothetical irrigation system to investigate how to allocate irrigation water to paddy fields in the district. Conversely to the other models previously mentioned, it emerged the stochastic nature of the model. Irrigation scenarios were also assumed considering the uncertainty of hydrologic and hydraulic factors.

These kinds of investigations into rice farming in temperate areas are instead still underdeveloped. Up to now, based on our knowledge, the only evidence of a multi-objective problem applied to rice is included in Bartolini et al. [36], who developed a multi-attribute linear programming model to simulate the impacts on Italian irrigated farms of modifications in water and agricultural policy.

To fill this gap, the paper introduces a deterministic multi-objective optimization model, based on real data obtained from field experiments. The model is applied to a homogeneous area in 
the rice-growing district of Northern Italy, and aims at investigating how competing objectives can be reconciled by managing irrigation water. Economic and environmental returns, i.e., gross margins and water saving, are included in a linear programming problem and simultaneously maximized under different levels of water availability, which in turn simulate water use conflicts and climate change repercussions.

\section{The Study Area}

Programming models for water allocation in agricultural production mostly operate at the regional scale. This allows exploring the optimal solutions from a policy-makers perspective, especially when sufficient homogeneity is observed across the region and it can be considered as a large farm [37]. Each study area should be large enough to contain a significant number of farms, while the focus on an "irrigation unit" would avoid introducing sources of variation related either to agro-climatic or economic conditions [38].

On these bases, a homogeneous rice-cultivated area has been circumscribed within the Pavia province, Lombardy region (Figure 1a), as the largest part of the rice-cultivated district in Northern Italy.

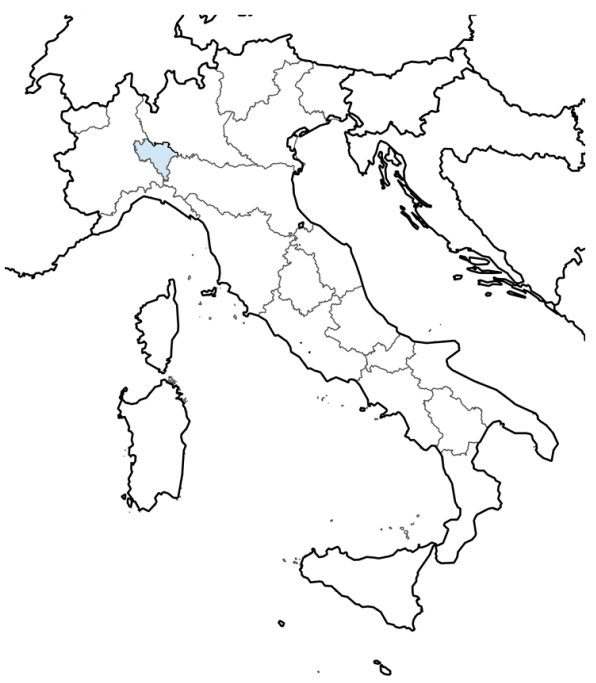

(a)

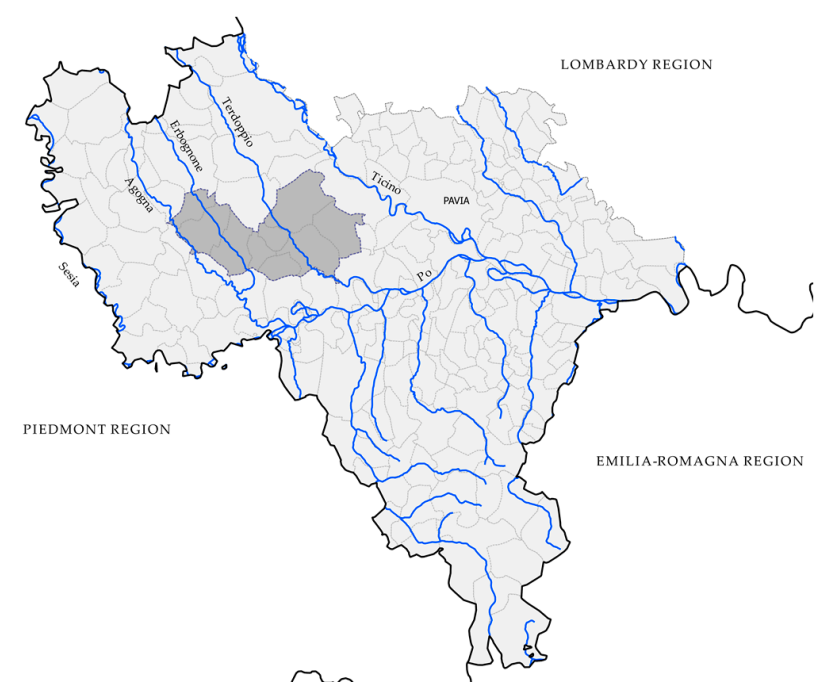

(b)

Figure 1. Location of the study area: (a) Pavia province, Lombardy region; (b) the study area.

With more than 80,000 ha in 2015 [39], the province is the first area in Italy for rice production, though other irrigated crops are also present, from maize to permanent grasslands and short rotation forestry (i.e., poplar groves). This combination in the production pattern may determine conflict in the use of water resource [25], given the specific water demand during the cropping season and the weather-climate trend; despite this, the largest part of irrigation water is here required by rice, since it is the most spread irrigated crop. In this sense, interventions targeted to this sector would have strongly repercussions on regional agriculture as a whole.

Water administration is assigned to the Water User Association Associazione Irrigazione Est Sesia, which annually supplies water to 161,880 ha of farmland in the period April-September. It operates at a smaller scale through its Local Units that manage a collective and consolidated irrigation network system made up of rivers, primary and secondary channels. Once supplied with water, rice-growers may decide to make a different use of it, based on to their actual needs; thus, alternative strategies for water management in paddy fields are already practiced and have been progressively spreading: since the last decade, the conventional cultivation technique, namely water seeding and continuous flooding, has been observing a reduction $(-38 \%)$ in favor of dry-seeded drill-sown rice $(+53 \%)$, which reached more than 50,000 ha in 2015 [39]. 
In this wider context, the study area is a portion of territory within the same irrigation unit, still pertaining to the aforementioned WUA. The focus on such a local scale better allows assessing the sustainable use of water, as suggested by Massarutto [40]. The area encompasses nine contiguous municipalities west to Pavia city (Figure 1b), with a total land size of $189 \mathrm{~km}^{2}$. A strong orientation to agriculture characterizes the area, with the 0.59 hectares of utilizable agricultural area available per capita mainly intended for permanent grassland and arable crops (Figure 2). In this irrigated farming system, a large number of farms with a similar productive specialization are mixed with others not considered in the analysis. In particular, rice cultivation, which involves 270 farms, prevails over other agricultural land-based activities: with an incidence on arable land at municipal-level ranging from $64 \%$ to $90 \%$, it counts for total 10,207 ha $(75.4 \%$ of arable land) [41].

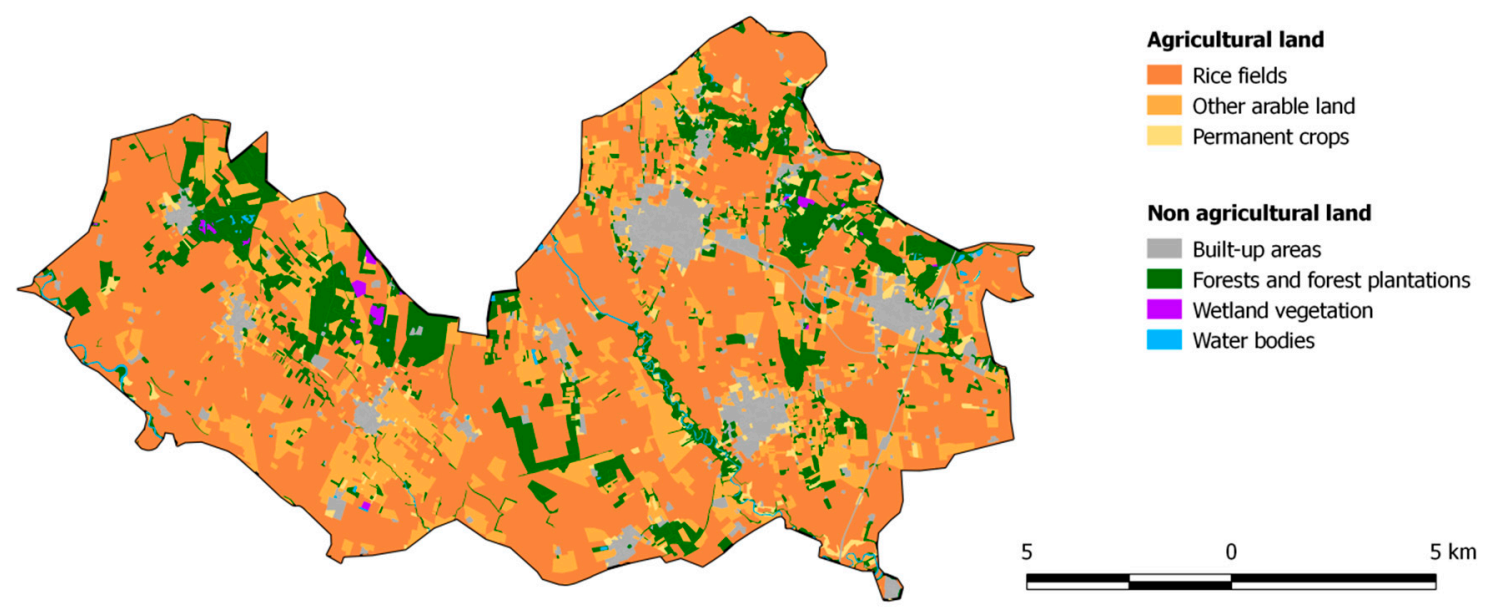

Figure 2. Land use in the selected area (source: own elaboration on DUSAF [42]).

Rice cultivation is mainly performed under continuous submergence, with a ponded water depth maintained for most of the growing season. A minority of paddy fields are subject to border irrigation, especially whenever water is delivered on rotation of 7 or 15 days [10,26].

\section{Water Management Options}

As pointed out by Graveline [37], the regional-scale modeling permits the reduction of data needed and ensures the quality of data employed. At the same time, field-level water management strategies play an important role as basic elements for water use efficiency [43]. From this perspective, water management options considered in the analysis and their respective irrigation amounts, specifically refer to field experiments performed at the Rice Research Centre of Ente Nazionale Risi at Castello d'Agogna (Pavia province), over the cropping seasons from 2011 to 2014. The experiment site is nearby the study area, and this makes sure that their own results-imputed to the model as described in the following paragraphs-may find practical adoption.

Treatments carried out concerned cultivation practices differing for sowing modality, water management and irrigation method [10,44]:

- Traditional method (FLD). Rice is sown directly into the water that submerges fields immediately after tillage operations, typically in April. Water is maintained on the field for the whole crop cycle, except for brief periods when treatments with herbicides or fertilizations are operated;

- Semi-traditional cultivation (DFL), which implies the dry seeding of drill-sown rice and the delayed flooding of paddy fields at the 3-leaf stage. The complete submersion of fields is completed approximately in late May-early June, then water management is similar to the previously described condition; 
- Dry cultivation, or aerobic rice (IRR). Rice is sown into dry soil before the first irrigation intervention, without any flooding taking place; rather, indeed, the field is irrigated intermittently, typically by border irrigation. The terrain modeling carried out over the decades led to the creation of large and horizontal sections; water management thus likely consists in short submersions, which may last few days, alternate to longer dry periods.

Their respective irrigation amounts, as measured and monitored at field scale [44,45], are shown in Table 1. The irrigation volume applied actually consists in providing more water than the amount needed, which means draining the excess $[25,46]$. Such water outflow from the field should not be however considered a loss; rather, water surplus is reused in either downstream or adjacent fields, and thus contributes in their irrigation, either by flooding irrigation or not. This way, water is re-circulated within a closed system, such as that managed at district- or irrigation area-level. In addition, because of this, more reasonable water volumes correspond to the net irrigation amounts, as the difference between irrigation inflows and outflows discharges. In the second instance, the amounts of water saved have been calculated for both the alternative management strategies, namely DFL and IRR, with respect to the conventional flooded condition (FLD).

Table 1. Irrigation and water saving amounts of different water regimes. Both the elements are expressed in $\mathrm{mm}$.

\begin{tabular}{ccc}
\hline Water Management & Net Irrigation & Water Saved \\
\hline FLD & 2275 & - \\
DFL & 1760 & 5150 \\
IRR & 680 & 15,950 \\
\hline
\end{tabular}

To each irrigation modality, the respective productive results have been associated, by quantifying both total revenues and production costs and combining them into the gross margin.

More often, crop yield enters predictive and simulation models by means of a crop-water production function; it thus derives that the effect of water saving (if any) can be explicitly expressed in comparison with farmers' net revenue achieved with that yield. Thus, the revenue of each water management combines the respective obtained yield (metric tons/ha) with the post-harvest farm-gate price $(€ / t)$ of paddy rice [47].

Two different sets of yields for each irrigation strategy have been included in the analysis (Table 2). The former refers to the average yields of a panel of four rice varieties (i.e., Baldo, Gladio, Loto and Selenio cultivars) representative of the main grain types, measured in the time span 2011-2014 at the aforementioned experiment fields [31,45]. As Borrell et al. [48] observed in a semi-arid tropical environment, irrigation water strongly influences the yield of rice. Similarly, in the study area, though a temperate rice-system, various irrigation practices allowed obtaining grain yields significantly different, with productions of submerged conditions higher than periodic irrigations [45]. This latter technique is in fact associated with a lower production potential, due to the greater environmental stresses the crop is subject to.

Table 2. Average yield of the three water management options, for traditional and innovative cultivars. Terms expressed in metric tons/ha.

\begin{tabular}{ccc}
\hline Water Management & Traditional cv. & Innovative cv. \\
\hline FLD & 9.6 & - \\
DFL & 9.3 & 10.8 \\
IRR & 7.7 & 7.8 \\
\hline
\end{tabular}

In addition, it is also considered the possibility of introducing for DFL and IRR innovative cultivars more suitable for dry cultivation. In this regard, the respective yield refers to the average yield of the 
top- 5 most productive breeding, selected by CREA amongst 100 experimental varieties specifically intended for semi-aerobic and aerobic conditions: a higher productivity for the DFL condition is evident, whereas grain production in IRR is quite similar to traditional cultivars.

An array of direct costs related to rice cultivation, as included in Camera di Commercio di Vercelli [49], has served as the basis to quantify rice production costs under different water management options. Starting from elaboration of data provided, production costs for FLD have been found to be $1998 € /$ ha; this is consistent with quantifications that demonstrated they vary between $1470-1500 € /$ ha [50,51] and $2430 € /$ ha [52]. Total production costs have been explicitly derived for the other water management practices as well, resulting in 1975 and $2052 € /$ ha for DFL and IRR respectively, which mean $+1.2 \%$ and $-2.7 \%$ if compared to FLD. Differences amongst treatments are not to be found in the cost of water supply, since the WUA applies a water tariff based on the extent of irrigated farmland and not on the actual volumes delivered to farms. Production costs rather primarily depend on the expenses related to water management. The various options, in fact, provide that a different number of watering operations occur during the cropping season. These interventions are coupled with labor related to the control and the regulation of the operations themselves. Thus, the adoption of DFL enables savings in labor needed to water management; in contrast, the more irrigation interventions, the higher water management costs, as evident especially in the IRR condition. In addition, as the result of water practice and especially in aerobic conditions, different agronomic and weed control operations may be necessary. In this case, they affect total production costs in terms of labor, mechanization, energy (i.e., for consumables) and other technical factors utilized, namely chemical fertilizers and herbicides.

Finally, the gross margin ( $€ /$ ha), used as a proxy for farmers' income, has been calculated accordingly, as the difference between revenues and production costs.

\section{The Methodological Approach}

\subsection{Multi-Objective Optimization}

When optimal decisions need to be taken in the presence of trade-offs between conflicting objectives, the adoption of a multi-criteria approach is encouraged. From this perspective, the final choice represents a compromise between different objectives [53]. In the wider context of decision modeling, mathematical programming assumes the role of a privileged instrument for providing general solutions to such complex problems, by formulating a multi-objective design problem.

Different techniques can be used to estimate all the feasible solutions, i.e., the optimal levels of resources allocation, for a certain number of alternative scenarios. From this perspective, linear programming-based models have been widely adopted in managing irrigated agriculture concerns, thanks to their easy formulation and use [54,55]. Multi-objective linear programming implies that both the objectives and the constraints they are subject to should be mathematically expressed in linear terms. In particular, each objective function $J_{\mathrm{i}}(x)$ is a function of the decision variable $x_{\mathrm{n}}$ to be optimized

$$
\operatorname{Max}\left(\text { or Min) }\left[\begin{array}{c}
J_{1}(x) \\
J_{2}(x) \\
\vdots \\
J_{\mathrm{i}}(x)
\end{array}\right]=\left[\begin{array}{cllc}
r_{11} & r_{21} & \cdots & r_{\mathrm{n} 1} \\
r_{12} & r_{22} & \cdots & r_{\mathrm{n} 2} \\
\vdots & \vdots & \cdots & \vdots \\
r_{1 \mathrm{i}} & r_{2 \mathrm{i}} & \cdots & r_{\mathrm{ni}}
\end{array}\right]\left[\begin{array}{c}
x_{1} \\
x_{2} \\
\vdots \\
x_{\mathrm{n}}
\end{array}\right]\right.
$$

where $J_{1}(x), \ldots, J_{\mathrm{i}}(x)$ are the objective functions that are simultaneously maximized or minimized, $\mathrm{n}$ the number of decision variables and $r_{\mathrm{ni}}$ their known coefficients. Decision variables, once adjusted, 
allow defining different efficient alternative configurations of the system under analysis. They may be subject to the non-negativity condition

$$
\left[\begin{array}{c}
x_{1} \\
x_{2} \\
\vdots \\
x_{n}
\end{array}\right] \geqslant 0
$$

whereas the multi-objective problem (1) is subject to a set of linear constraints

$$
\left[\begin{array}{cccc}
a_{11} & a_{12} & \cdots & a_{1 \mathrm{n}} \\
a_{21} & a_{22} & \cdots & a_{2 \mathrm{n}} \\
\vdots & \vdots & \vdots & \vdots \\
a_{\mathrm{m} 1} & a_{\mathrm{m} 2} & \cdots & a_{\mathrm{mn}}
\end{array}\right]\left[\begin{array}{c}
x_{1} \\
x_{2} \\
\vdots \\
x_{\mathrm{n}}
\end{array}\right] \leqslant \geqslant\left[\begin{array}{c}
q_{1} \\
q_{2} \\
\vdots \\
q_{\mathrm{m}}
\end{array}\right]
$$

with $a_{\mathrm{mn}}$ the known coefficients of decisional variables and $q_{\mathrm{m}}$ the upper or lower limits of the constraints.

\subsection{The Optimization Model}

Ensuring the profitability of rice-cultivation and water saving are prime objectives in this study. Based on linear programming, a multi-objective problem has been implemented accordingly. It concerns the optimal allocation of rice land (xrice) amongst different water management options, performed under progressive reductions in the amount of irrigation water (i.e., the $s$ scenarios) supplied by the WUA. Irrigation water thus enters the model both directly, through available water amounts, and indirectly, by means of net water volumes distributed through each $m$ irrigation practice.

The implemented model was aimed at exploring the trade-offs between economic and environmental objectives in each scenario $s$; in addition, the effects of a possible introduction of cultivars selected for dry-cultivation have been estimated. More in detail, the first objective function maximizes total regional income $(€)$, as related to gross margins

$$
J_{1, \mathrm{~s}}=\sum_{\mathrm{m}} \mathrm{GM}_{\mathrm{m}, \mathrm{s}} \times \mathrm{xrice}_{\mathrm{m}, \mathrm{s}}
$$

while the second concerns the maximization of irrigation water saved in the area $\left(\mathrm{m}^{3}\right)$

$$
J_{2, \mathrm{~s}}=\sum_{\mathrm{m}} \mathrm{WS}_{\mathrm{m}, \mathrm{s}} \times x \text { rice }_{\mathrm{m}, \mathrm{s}}
$$

In order to avoid any scale dependency due to different dimensions of the two objective functions, they have been normalized into the [0-1] interval by using the respective maximum achievable values as the normalization constants. Equations (4) and (5) become

$$
J_{1, \mathrm{~s}}^{*}=\frac{\sum_{\mathrm{m}} \mathrm{GM}_{\mathrm{m}, \mathrm{s}} \times x \text { rice }_{\mathrm{m}, \mathrm{s}}}{\max \sum_{\mathrm{m}, 0} \mathrm{GM}_{\mathrm{m}, 0}}
$$

and

$$
J_{2, \mathrm{~s}}^{*}=\frac{\sum_{\mathrm{m}} \mathrm{WS}_{\mathrm{m}, \mathrm{s}} \times x \text { rice }_{\mathrm{m}, \mathrm{s}}}{\max \sum_{\mathrm{m}, 0} \mathrm{WS}_{\mathrm{m}, 0}}
$$

Therefore, the values of the individual objective functions have been assumed to vary within the predefined ranges and express the percentage of achievement of their respective maximum levels.

In order to solve the multi-objective problem, the weighting method has been adopted. It consists in assigning a weight $w_{\mathrm{i}, \mathrm{s}}$ to each $J_{\mathrm{i}, \mathrm{s}}^{*}$, as the expression of the relative importance of the various 
objectives, and can be solved for various sets of weights. The function of the optimization model is then expressed in the form

$$
\operatorname{Max} \sum_{\mathrm{i}} w_{\mathrm{i}, \mathrm{s}} J_{\mathrm{i}, \mathrm{s}}^{*}(x)=w_{1, \mathrm{~s}} \times J_{1, \mathrm{~s}}^{*}(x)+w_{2, \mathrm{~s}} \times J_{2, \mathrm{~s}}^{*}(x)
$$

The weights $\mathrm{w}_{\mathrm{i}, \mathrm{s}}$ relating to each $J_{\mathrm{i}}^{*}$, are assumed to vary within the [0-1] interval

$$
\sum_{\mathrm{i}} w_{\mathrm{i}, \mathrm{s}}=1
$$

with 0 for the more adverse and 1 for the most advantageous result, respectively.

The number of alternative problems the method should solve is equal to $k^{i-1}$, where $k$ is the number of values given to the weights and $i$ the number of the objective functions included in the model. Different sets of weights have been adopted to assign priorities to economic result, water saving or a balance between them. In particular, all the possible weighting schemes included in the defined range have been initially used for the computations, to reflect the effects of objective prioritization on the final resolution and depict accordingly the trend of the multi-objective function.

The model is subject to the non-negativity condition of decision variable:

$$
x \text { rice }_{\mathrm{m}, \mathrm{s}} \geqslant 0, \forall m, s
$$

and further two different constraints, regarding the availability of land and water resource.

Firstly, the land balance ensures that total rice-growing area may either decrease or increase, up to, in this latter case, cover all the available arable land UAA_arable

$$
\sum_{\mathrm{m}} x \text { rice }_{\mathrm{m}, \mathrm{s}} \leqslant \text { UAA_arable, } \forall m, s
$$

Secondly, the availability of water is run in all the scenarios under the condition that net irrigation volumes $N I\left(\mathrm{~m}^{3} / \mathrm{ha}\right)$ should not exceed the $q\left(\mathrm{~m}^{3} / \mathrm{ha}\right)$ seasonal amount of water supplied by the WUA:

$$
\sum_{\mathrm{m}}\left(x \text { rice }_{\mathrm{m}, \mathrm{s}} \times N I_{\mathrm{m}}\right) \leqslant q \times \text { UAA_arable, } \forall m, s
$$

\section{Results}

\subsection{Optimization of Current Situation}

The optimization of the original configuration under the current level of water availability $\left(q=3.6 \mathrm{~L} / \mathrm{s} \cdot \mathrm{ha}^{-1}\right)$, reveals how the objective function varies according to the set of weights assigned to the final formulation (Figure 3).

The maximum value of the objective function is observed whenever the optimization is run with $w_{1}$, or alternatively $w_{2}$, equal to 0 , which means reducing it to a one-objective problem. In these cases, the respective components $J_{\mathrm{i}}$ achieve their maximum (minimum) possible value. Given the aforementioned behavior, it derives that with all the other weights sets, both the $J_{\mathrm{i}}$ do not satisfy such a condition; rather, indeed, they show an opposite and complementary trend, which is reversed for $w_{1}$ close to 0.60 . Before this benchmark, the optimal value of water saving (i.e., $J_{2}$ ) prevails over economic returns; conversely, a higher contribution in the final value of the objective function itself is due to the economic aspect. Over this inflection point the objective function further decreases up to get to its lowest value (0.75) for $w_{1}=0.61$. A marked change in the performances of individual $J_{\mathrm{i}}$ then occurs, as well as for objective function as a whole. This latter follows an ascending trend and in correspondence of $w_{1}=0.95$ another inflection point is evident, with the function reaching the upper limit. 


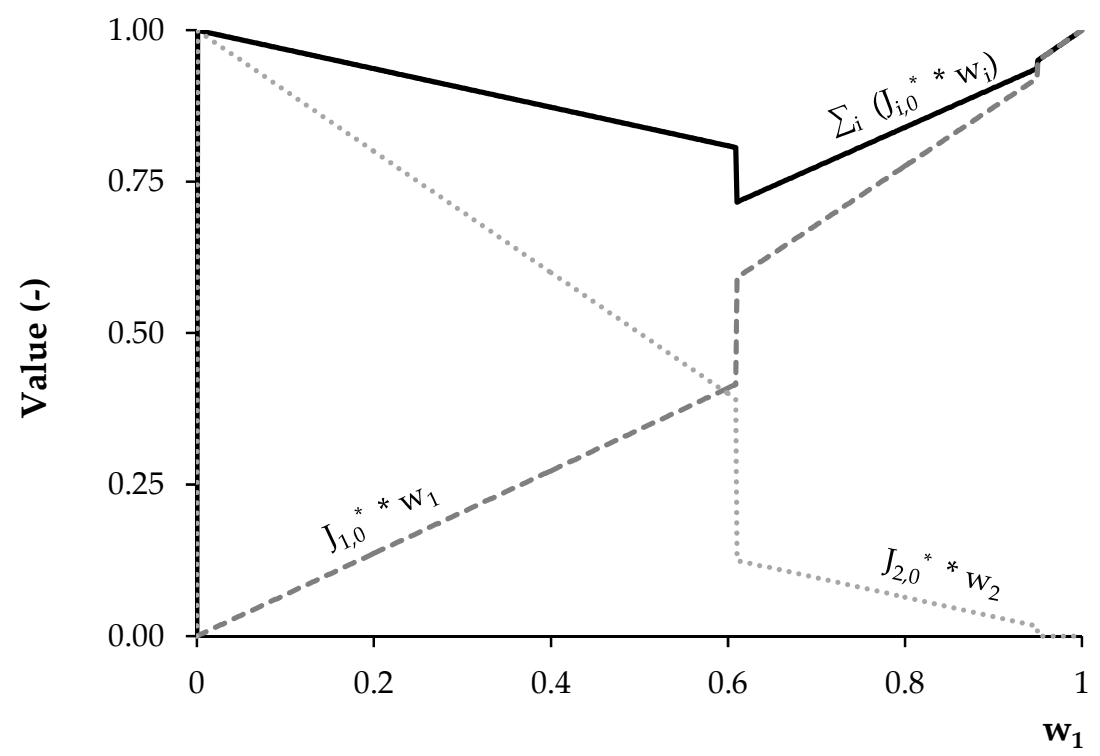

Figure 3. Performance of the two-objectives function and its components in the current situation.

This behavior is the basic element that determines the optimal allocation of land amongst different irrigation practices (Figure 4). On one hand, given data input and the constraints imposed to the model, the maximization of water saving $\left(w_{1}=0\right)$ would suggest not to practice irrigated agriculture. However, to avoid gross margin not to be generated $\left(w_{1}>0\right)$, the area intended for rice increases by $33 \%$ if compared to the current extent, up to cover all the available arable land.

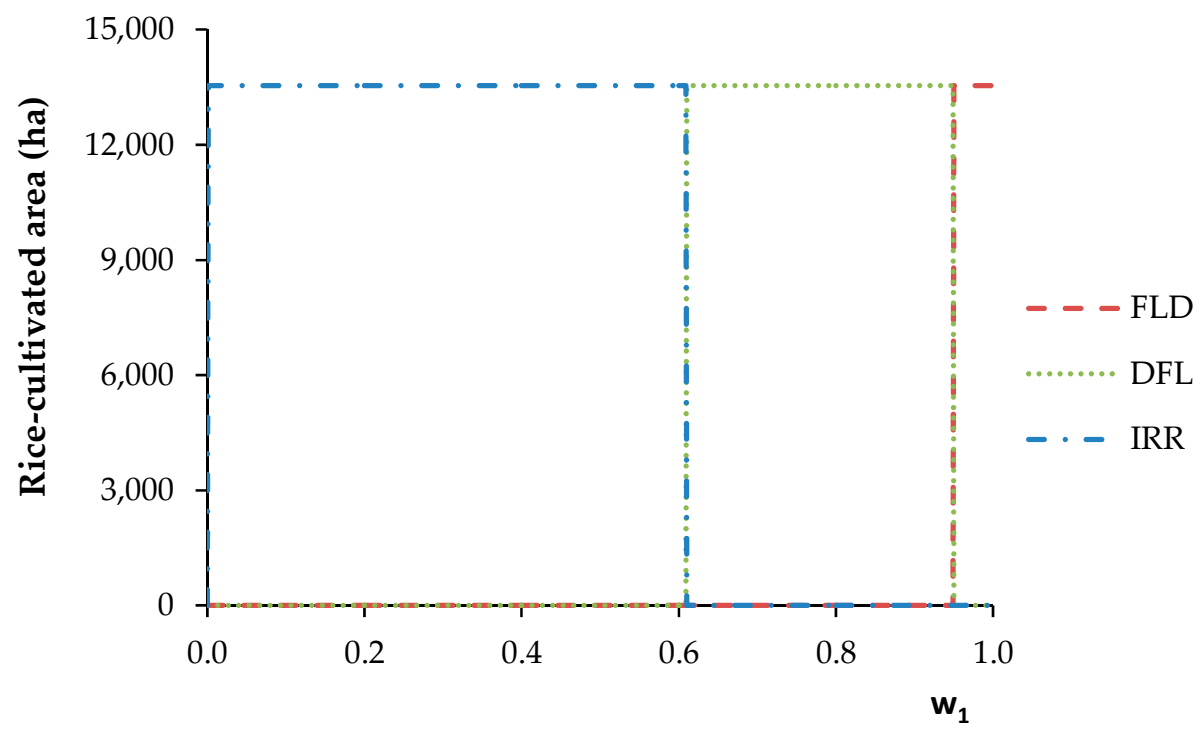

Figure 4. Rice-cultivated area under different irrigation practices.

From this perspective, any coexistence between either different agronomic managements or irrigation practices is favored. These latter are rather sequentially returned starting from the benchmarks previously identified, namely $w_{1} \in\{0,0.61,0.95,1\}$, which determine different system configurations.

Dry-seeded rice (DFL and IRR) can benefit from both water saving and economic return, being preferred when $\mathrm{w}_{1}$ ranges up to 0.95 . More in detail, aerobic rice and flush irrigation (IRR) is encouraged for most of the possible weights combinations, with particular regard to prioritization of 
water saving, but also if it slightly prevails over economic results $\left(0.5 \leqslant w_{1} \leqslant 0.6\right)$ : this is the strategy a balance between the two conflicting objectives corresponds to.

The prevalent role of maximizing gross margins suggests adopting flooding irrigation, possibly delayed, which ensures highest revenues and lower production costs. In the case of FLD, given that no water is saved and the variation in gross margin over DFL is scarce $(+74 € / \mathrm{ha})$ (Figure 5$)$, it is preferred only if to the economic component is given much more importance ( $w_{1}$ close to 1$)$.

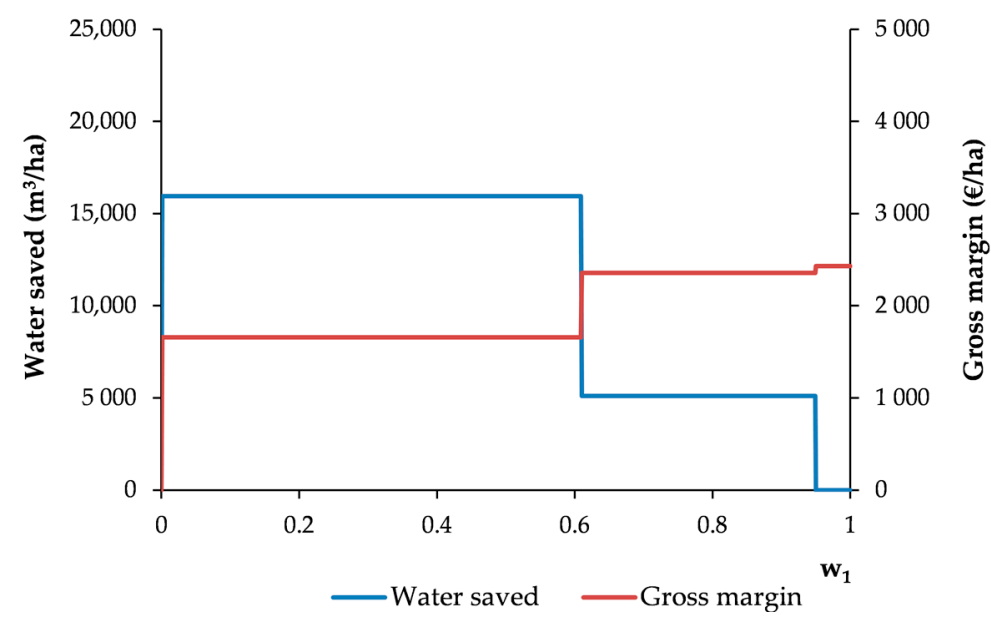

Figure 5. Water saved and gross margin with different sets of weights.

Still ensuring the same amount of water saved, the introduction of more productive cultivars increases the regional gross margin. Such a possibility is however limited to dry and semi-dry cultivations. Introducing the innovative cultivars specifically selected would enhance economic results especially because of a higher yield, rather than different production costs. From this perspective, gross margins undergo an augmentation by $16 \%$ in the DFL condition, whilst by only $1.3 \%$ in IRR (Figure 6). On the other hand, no additional gross margins can be obtained with the maintenance of the traditional flooded condition. In this case, higher profits should derive from a different exploitation of available resources.

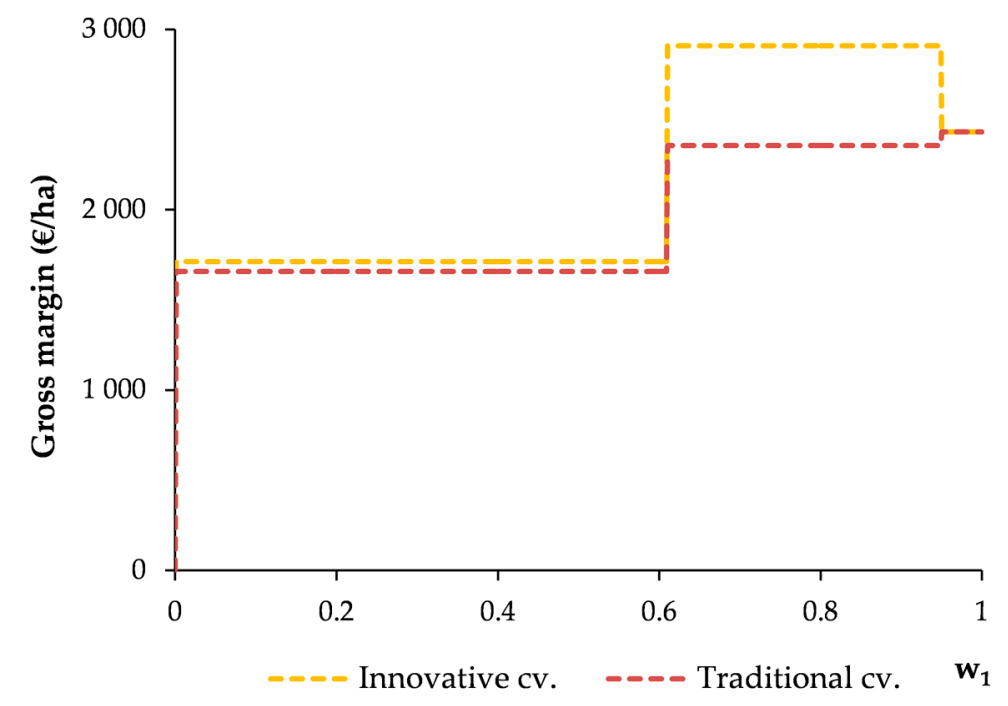

Figure 6. Trend of gross margins following the introduction of innovative cultivars.

To provide indications about the response of the economic performance under a real (if any) water saving, the trade-offs between the two targets have been quantified (Table 3). They express 
the additional gross margin following a unit variation in the water saved, compared to the FLD condition. This indication once again demonstrates how the economic and the environmental aspects are conflicting one another, given their opposite trends. Both DFL and IRR are in fact coupled with a loss of 0.01 and $0.05 € / \mathrm{m}^{3}$ of water saved, respectively. This denotes productions to be unprofitable at the given prices and irrigation levels, with total losses quantified in $52 €$ and $798 €$. Following the adoption of innovative cultivars, their respective trade-offs shift to positive in the case of DFL $\left(+0.09 € / \mathrm{m}^{3}\right)$ and increase to $-0.04 € / \mathrm{m}^{3}$ for intermittent irrigations.

Table 3. Trade-offs between conflicting objectives per alternative water management and typology of rice variety.

\begin{tabular}{ccc}
\hline Water Management & Trade-off (Traditional cv.) $\left(\boldsymbol{(} / \mathbf{m}^{\mathbf{3}}\right)(\boldsymbol{(})$ & Trade-off $\left(\right.$ Innovative cv.) $\left(\boldsymbol{\epsilon} / \mathbf{m}^{3}\right)(\boldsymbol{\epsilon})$ \\
\hline DFL & $-0.01(-52)$ & $+0.09(+464)$ \\
IRR & $-0.05(-798)$ & $-0.04(-638)$ \\
\hline
\end{tabular}

\subsection{Scenario Analysis}

Solutions from the adoption of four sets of weights are comparatively examined under different levels of water availability, i.e. different scenarios (Table 4). Selected water flows correspond to those needed to sustain from time to time one of the management options (i.e., $s_{1}, s_{3}$ and $s_{5}$ ), and are integrated with other intermediate levels, represented by the second and the fourth scenario.

Table 4. Key parameters of water availability scenarios.

\begin{tabular}{ccc}
\hline Scenario & $q_{\mathbf{s}}\left(\mathbf{L} / \mathbf{s} \cdot \mathbf{h} \mathbf{a}^{-\mathbf{1}}\right)$ & $q_{\mathbf{s}}\left(\mathbf{m}^{\mathbf{3}} / \mathbf{h a}\right)$ \\
\hline$s_{1}$ & 2.19 & 22,706 \\
$s_{2}$ & 1.95 & 20,218 \\
$s_{3}$ & 1.70 & 17,626 \\
$s_{4}$ & 1.18 & 12,234 \\
$s_{5}$ & 0.66 & 6843 \\
\hline
\end{tabular}

As previously demonstrated (see Figure 4), land allocation amongst the possible cultivation strategies remains unchanged within specific ranges of values bounded by precise combinations of weights. On this basis, the analyses introduced in this section focus on economic and environmental results observable at the lower bounds of these ranges; in other words, it means adopting the analytical approach only in correspondence of the different weights sets for which the optimization process determines, from time to time, a different configuration of the system. More in detail, they are identified as the benchmarks described above, obtained for $w_{1}=0.61,0.95$ and 1 respectively; in addition a balance between the two objective functions $\left(w_{1}=0.5\right)$ has been taken into account as well, while the condition that maximizes water saving $\left(w_{1}=0\right)$ is excluded from the analysis, as it returns null areas in all the scenarios, suggesting not to practice irrigated agriculture. Finally, two different initial conditions are optimized. In the former only traditional varieties are included; in the second configuration, the model can choose if adopting them or not, preferring in this latter case, breeding more suitable for dry cultivation.

In general terms, as shown in Figure 7, optimization suggests to make use of all the available agricultural area, despite different conditions of both water availability and priority given to the objectives considered. A decreased irrigation amount available to farmers, encourages less water-demanding techniques, with flush irrigation (IRR) particularly favored when priority is given to water saving. This is also the most favored option when environmental and economic concerns are equally accounted for ( $w_{1}$ up to 0.5 ). On the other hand, more positive economic results are to be found in presence of submerged rice fields, whenever this practice is effectively sustained by the irrigation water available. Different irrigation volumes supplied may, in fact, enable only one or 
more resource management strategies. The water flow set in $s_{1}\left(2.9 \mathrm{~L} / \mathrm{s} \cdot \mathrm{ha}^{-1}\right)$ leads the model to choose optimal land allocation amongst all the management options, given that it corresponds to a volume per hectare $\left(22,706 \mathrm{~m}^{3} / \mathrm{ha}\right)$ higher than each net irrigation amount needed (see Table 1 ). In this case, water management options are sequentially returned according to the relative importance recognized to each objective function. Conversely, lower water availability $\left(s_{2}\right)$, if mainly aimed at maximizing gross margins, primarily suggests to introduce delayed flooding at the expense of FLD. The area intended for conventional cultivation is further gradually replaced by alternative strategies, the less is the water available. $1.70 \mathrm{~L} / \mathrm{s} \cdot \mathrm{ha}^{-1}\left(q_{3}\right)$ permits to adopt DFL and IRR techniques only. In this sense, the former is encouraged when maximization of gross margin is preferred over water saving, the latter in the opposite situation. All these consideration are not entirely valid when optimization concerns a production pattern based on innovative cultivars. In such conditions DFL is the modality prevailing over the other irrigation practice (i.e., IRR), independently from both weights sets and water flow amounts: as demonstrated so far, the same allocation of resources is in fact returned by different scenarios.

Similarly to $s_{2}$, the fourth scenario returns the possibility to practice two different water management strategies at once, with half of the area intended for DFL and the rest for IRR, despite different priority given to the objectives, especially when the introduction of ameliorated cultivars is considered. Finally, the last condition simulated $\left(s_{5}, 0.66 \mathrm{~L} / \mathrm{s} \cdot \mathrm{ha}^{-1}\right)$ implies that all the arable land is cultivated with drill-sown rice and its border irrigated, irrespective of both the rice variety and the main objective pursued. Actually, this is the only possible option, being the respective water amount ( $\left.6843 \mathrm{~m}^{3} / \mathrm{ha}\right)$ able to effectively ensure only such irrigation modality. Therefore, in this case the prioritization of the $J_{\mathrm{i}}$ functions does not affect the optimal solution, as well as the use of resource is not aimed at water saving as such, but rather at making the best use of irrigation water available.

Both irrigation water amounts and gross margins vary accordingly to the optimal allocation of rice-growing area, within a same scenario and across simulated conditions for a same initial configuration (Figure 8).

With particular regard to the original configuration of regional agriculture (see Figure 8, left column), they both increase within a same scenario and decrease with the level of water availability, except when water flows ensures only IRR (i.e., $s_{5}$ ) or either the economic and the environmental dimensions remain constant. In addition, the range of gross margins progressively decreases from 10.5 Mio. EUR in $s_{1}$ to 4.7 Mio. EUR in $s_{4}$, up to be cancelled when water availability represents the strongest constraint for rice-cultivation (Table 5), leading each farm to benefit from economic results that range between 83,103 and $121,874 €(1658-2431 € /$ ha).

In contrast, when optimization concerns the introduction of more productive varieties, the variation in the total gross margin is noticeable. A diminution occurs with a decreasing water availability, with $-21 \%$ when passing from $s_{3}$ (or, equivalently $s_{1}$ or $s_{2}$ ) to $s_{4}$, and $-26 \%$ from $s_{5}$ to $s_{4}(-41 \%$ compared to the first three conditions), whilst still remaining the same irrespective of the importance of the set objectives. For irrigation volume disposed, too, the same trend is evident. 

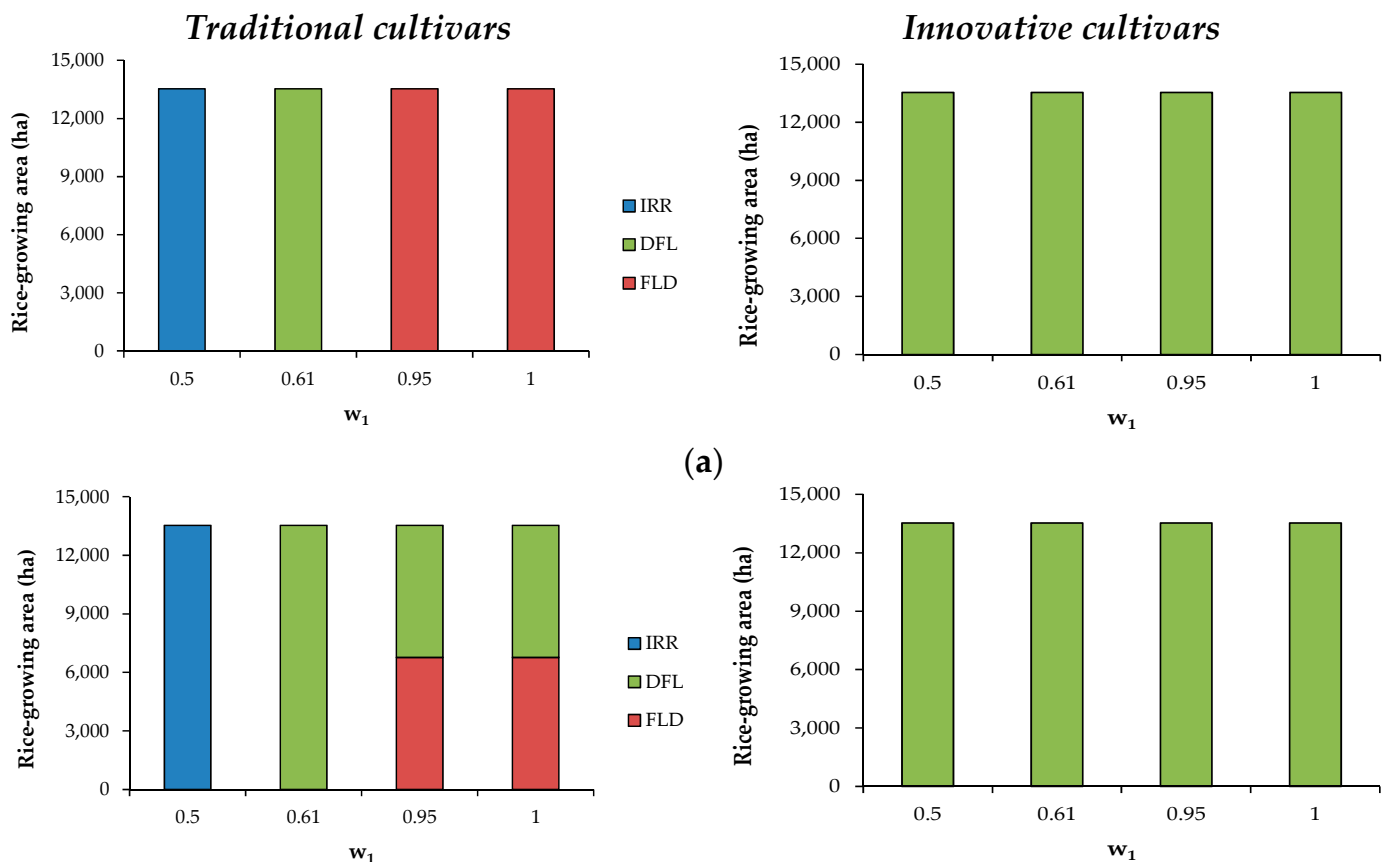

(a)
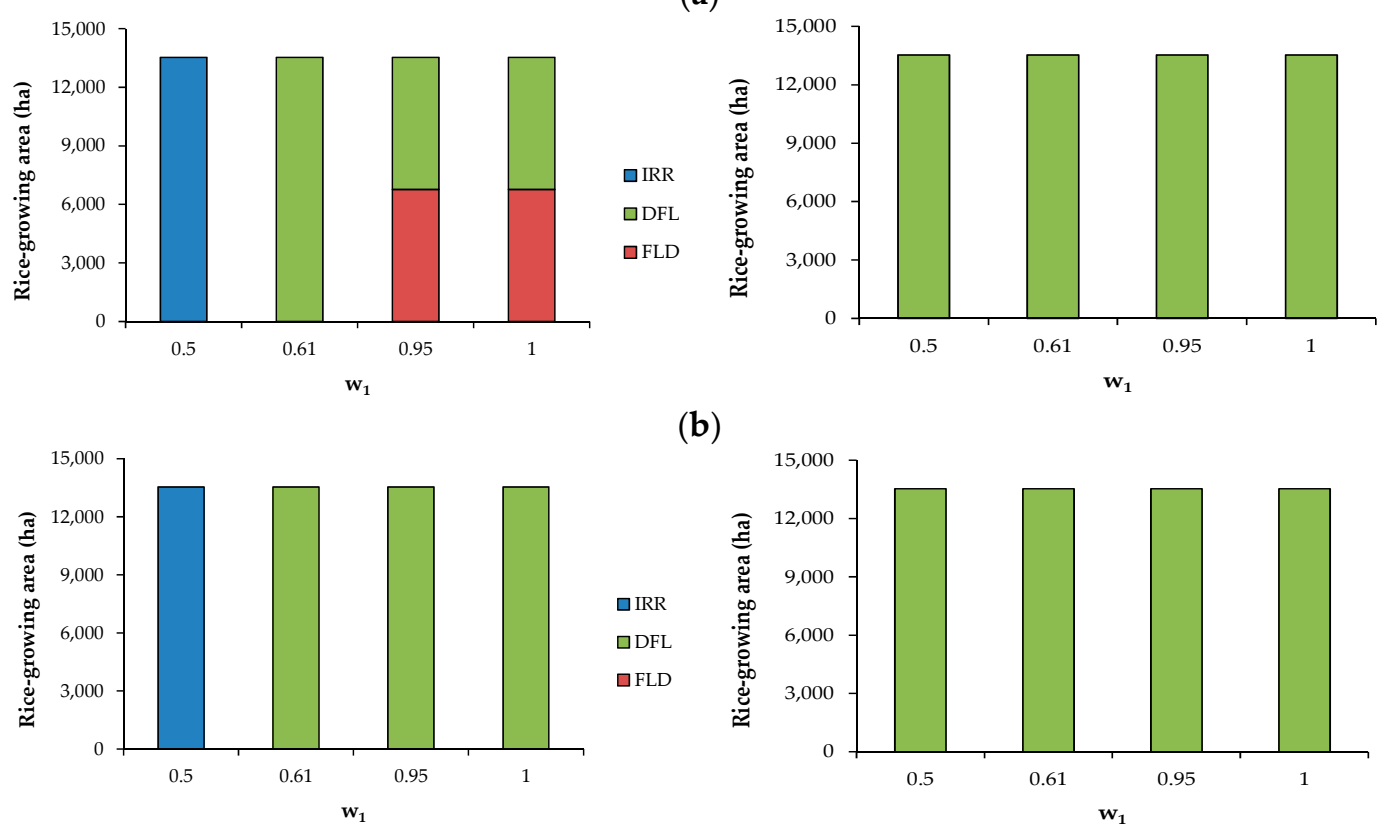

(b)
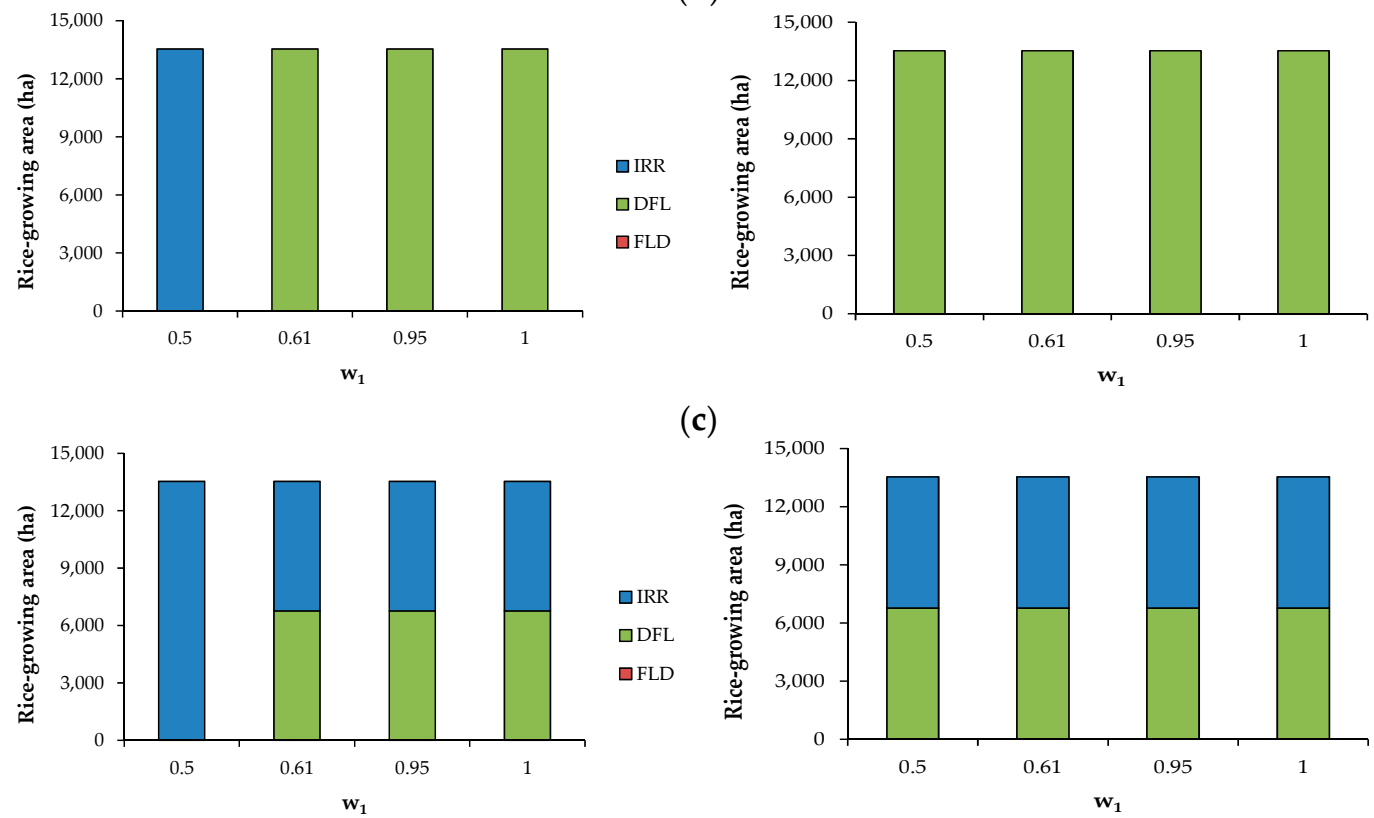

(c)

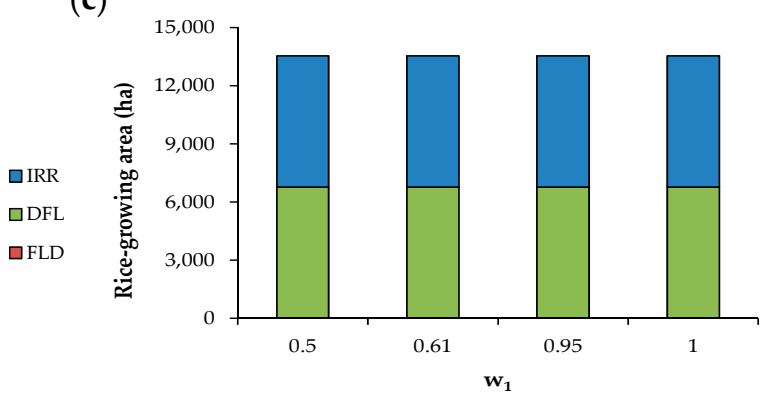

(d)
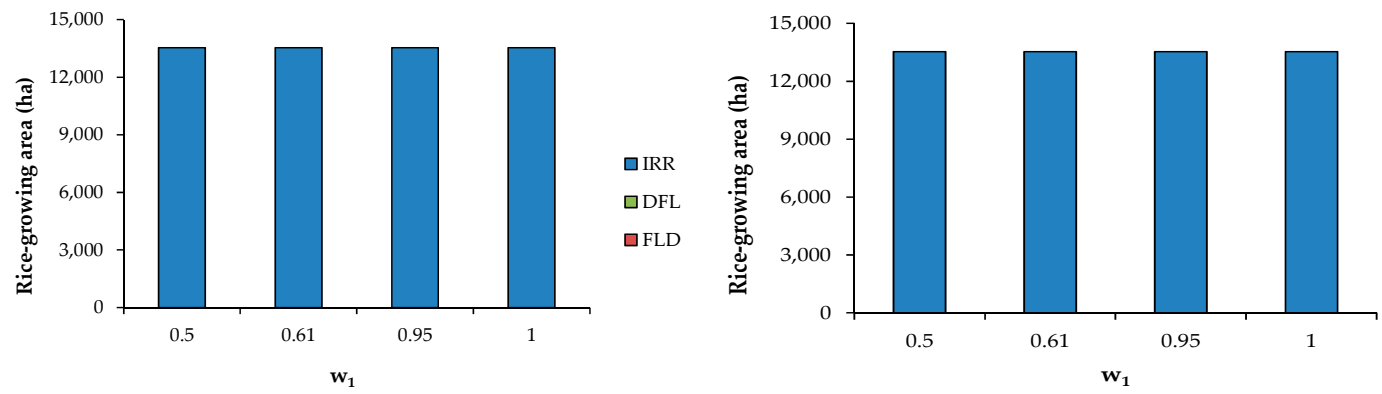

(e)

Figure 7. Optimal allocation of rice-growing areas under different water availability levels (i.e., scenarios): (a) $2.19 \mathrm{~L} / \mathrm{s} \cdot \mathrm{ha}^{-1}$; (b) $1.95 \mathrm{~L} / \mathrm{s} \cdot \mathrm{ha}^{-1}$; (c) $1.70 \mathrm{~L} / \mathrm{s} \cdot \mathrm{ha}{ }^{-1}$; (d) $1.18 \mathrm{~L} / \mathrm{s} \cdot \mathrm{ha}^{-1}$; (e) $0.66 \mathrm{~L} / \mathrm{s} \cdot \mathrm{ha}^{-1}$. Each scenario shows results of both prioritization weights and specific constraints: cultivation of traditional cultivars only or possible introduction of innovative cultivars. 
Traditional cultivars
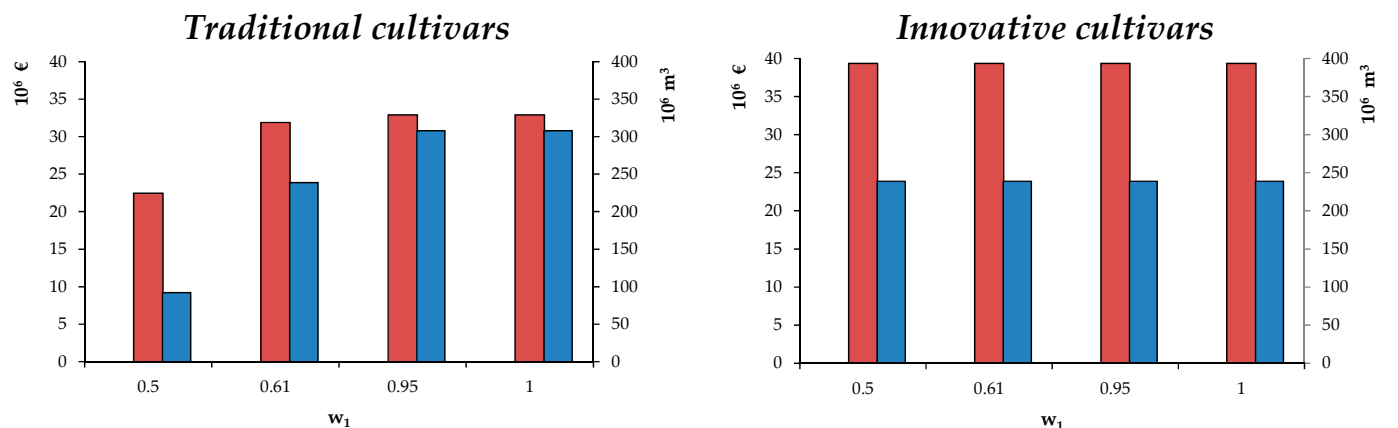

(a)
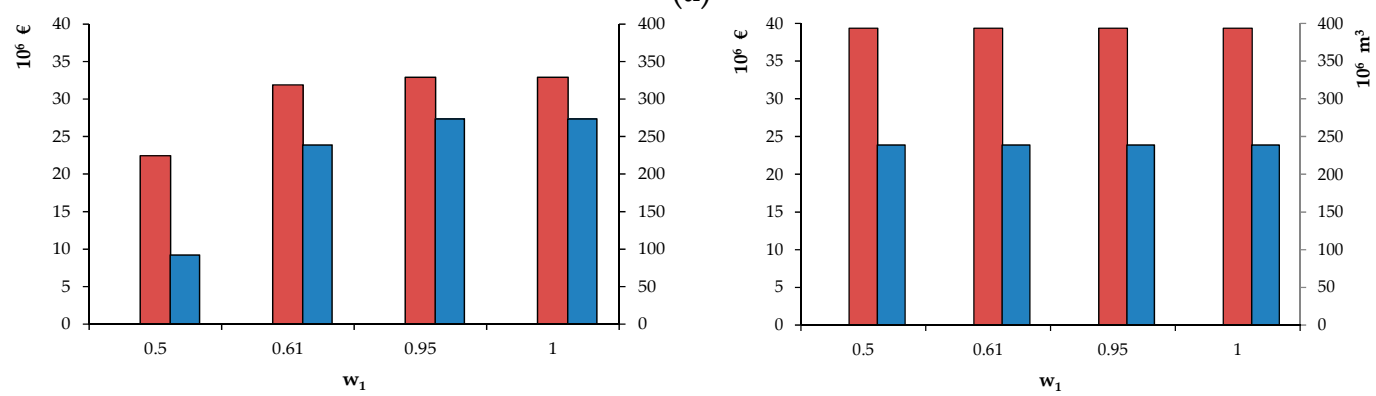

(b)
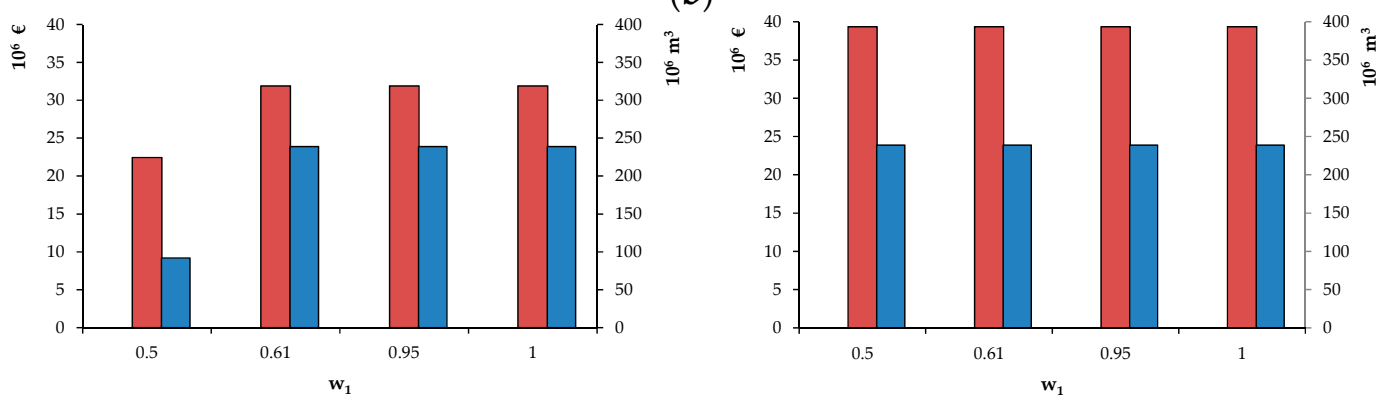

(c)
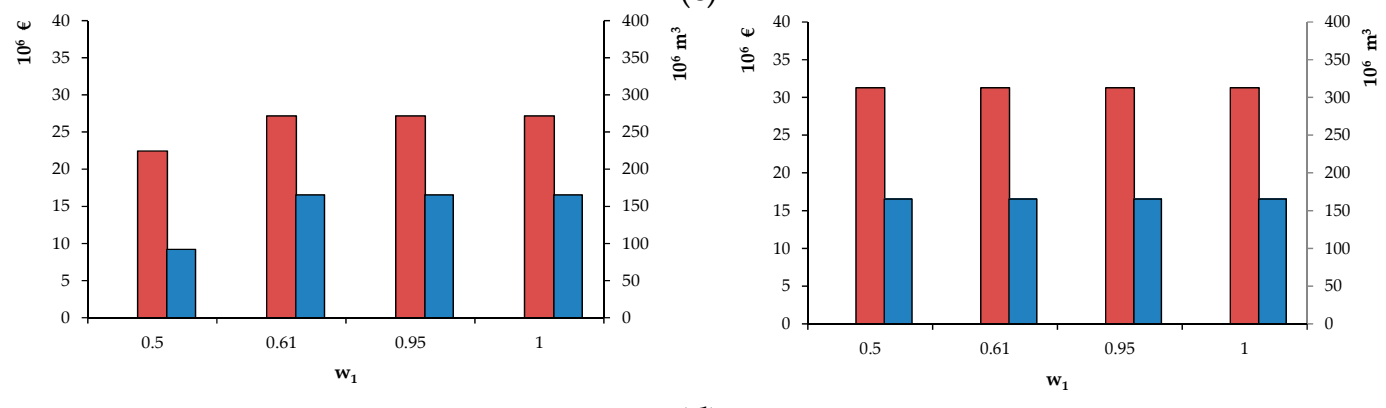

(d)
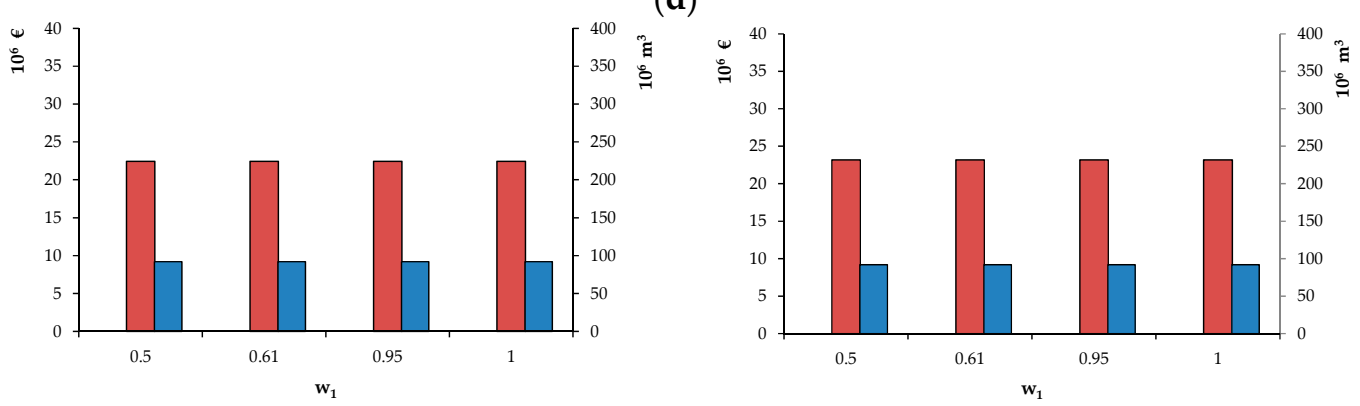

(e)

Figure 8. Gross margins (Mio. EUR, red series) and irrigation water amounts (Mio. $\mathrm{m}^{3}$, blue series) in the study area, under different water availability levels: (a) $2.19 \mathrm{~L} / \mathrm{s} \cdot \mathrm{ha}^{-1}$; (b) $1.95 \mathrm{~L} / \mathrm{s}^{\mathrm{h}} \mathrm{ha}^{-1}$; (c) $1.70 \mathrm{~L} / \mathrm{s} \cdot \mathrm{ha}^{-1}$; (d) $1.18 \mathrm{~L} / \mathrm{s} \cdot \mathrm{ha}^{-1}$; (e) $0.66 \mathrm{~L} / \mathrm{s} \cdot \mathrm{ha}^{-1}$. Each scenario shows results of both prioritization weights and rice varieties cultivated. 
Table 5. Gross margins (Mio. EUR) in the original configurations.

\begin{tabular}{cccc}
\hline Scenario & Min & Max & Range \\
\hline$s_{1}$ & 22.4 & 32.9 & - \\
$s_{2}$ & 22.4 & 32.9 & 10.5 \\
$s_{3}$ & 22.4 & 31.9 & 9.5 \\
$s_{4}$ & 22.4 & 27.2 & 4.7 \\
$s_{5}$ & 22.4 & 22.4 & 0 \\
\hline
\end{tabular}

\section{Discussion}

In general terms, the use of linear programming is a relatively simply approach to simulate a large variety of modifications in a regional agricultural system. Scenario analysis showed the role of modeling in deepening the possibility to still perform rice-cultivation; this could be strategic in economic terms not only for the whole area, but also for the resilience of specialized farms-which number, at least in Pavia province, has been suffering from a reduction [56] —and the achievement of targets set by water policies.

A varied array of water management options can be adopted in rice-cultivation, to stimulate the rational use of water resources. This is extremely necessary to face water scarcity and represents only a part of the sustainability applied to irrigated agriculture, since it concerns conflicting objectives and strengthens the wicked nature of the sustainability problem.

The innovative irrigation practices included in the analysis are coupled with different gross margins and water saving amounts, considered as simplified indicators for economic and environmental results in the study area. From this perspective, water price has a relevant role and impacts on both profit and water use [36]. In the context analyzed in the paper, water is supplied according to a tariff based on the extent of irrigated farmland. This has currently positive repercussions on the production cost of rice-growing farms, leading gross margins to be affected only marginally by water tariff, benefitting from it regardless the amount of water used. Thus, if farmers were charged with a volumetric fee, the production costs following both traditional and semi-traditional cultivation would be higher, due to increased water supply costs and decreased gross margins. It is also discussed that, despite such an increase, this would lead to a better resource allocation. The role of such a kind of tariff in encouraging water saving is widely recognized and promoted by international regulations, e.g., the Water Framework Directive (2000/60/EC). Future insights on the role of a volumetric water tariff are needed, in order to deepen how it concretely affects the regional economy and to reveal if and under which conditions rice-cultivation is still economically convenient.

Alternative water managements imply different production costs, according to the operative modalities adopted to conduct paddy fields, from fertilizations to weed control treatments. From this perspective, the chance emerges for applied research in selecting varieties that best suit dry conditions and perform higher yields, to counteract possible major production costs. Indeed, the introduction of short-cycle crops and genetically selected varieties, as well as the implementation of efficient methods of weeds control, would make such options more economically convenient for many farms.

Along with economic aspects, it is to be considered that in districts where irrigation has a long tradition, water supply systems are coupled with environmental concerns also related to multiple uses of the resource [57]. Rice-cultivation in the study area is the result of a long process of adaptation undertaken by agriculture to site-specific conditions, which has allowed over time to build a consolidated and traditional system made up of the interactions amongst natural resources and human activities. Such a complex stability is continuously managed to create an optimized system that reuses in downstream areas the losses of the upstream ones, thanks to springs, wells and leakages. It therefore derives that alternative allocations of both land and water may lead to significant modifications in the regional irrigated system. They are not entirely the results of farmers' decisions and their change could cause ecological and environmental effects not immediately identifiable. In this sense, the practical feasibility of suggested options should be carefully taken into account when pursuing specific aims: 
such marked changes could not be actually sustained by the current agricultural practices nor easily accepted by farmers.

Based on model results, some considerations about that in fact arise. When rice cultivation is not advantageous from a water saving point of view, all the arable farmland should be intended for non-irrigated crops or reconverted to permanent land uses (e.g., forest and forest plantations); such a reconversion, as long as the possibility in changing the crop mix, are actually subject to a wider set of other economic, environmental and cultural constraints, which lead to a more complex cultivation pattern variable over time. On the other hand, the expansion of rice-cultivated area is difficult to achieve. The chance to intend all the arable land for rice would moreover have strong economic and managerial repercussions on not specialized farms, which should adapt their cultivation methods in terms of agronomic strategies, use of machinery and technical factors to other or newly-implemented agricultural practices.

Intermittent irrigation is encouraged especially when water saving is preferred over the economic dimension, and whenever water availability becomes the limiting factor for ensuring traditional cultivation. The adoption on large areas of such a modality may also lead to encounter profound modifications in the soil water dynamics and balance. It would enable a significant decrease in irrigation requirements and, at the same time, lead water table to suffer from a reduced recharge, with cascading effects on groundwater resources that are further exacerbated by water scarcity. In a very similar way, an enhanced technical and infrastructural efficiency able to reduce water losses along distribution system, as long as a higher water use efficiency, operate as driving forces to optimize the use of resource under either water scarcity or droughts. Further implications in recharging and supplying water sources in general arise, possibly cancelling, especially at district-level, the potential benefits of water reallocation.

Notwithstanding, performing water saving techniques in rice-cultivation is a strategy that enables increasing water resource availability for augmented irrigated farmland, mitigates the effects of climate change or prevents them thanks to reduced greenhouse gasses emissions [45,58]. As a further environmental concern, submerged paddy fields and their long-term maintenance have created not only traditional local landscapes, but also agro-environmental habitats with peculiar ecosystem services. Water supply systems are here coupled with environmental aspects, therefore multiple uses of the resource should not be ignored [12]. Such high value areas are recognized at the community level, as part of the NATURA 2000 network, as well as on the list of both the Special Protected Areas and Site of Community Importance (Habitats Directive, 92/43/EEC); a conflict between irrigation water and water for natural ecosystems thus becomes more evident [12]. DFL seems to be the best compromise solution to be adopted, since it shows positive performances in terms of water saving ( $-23 \%$ compared to DFL), whilst ensuring adequate gross margins, especially if innovative cultivars are adopted. In this case, in fact, margins obtained with selected breeding are higher than with traditional ones, while maintaining water on the field for most of the growing season allows the permanence of wetlands and humid areas favorable to aquatic biodiversity.

As demonstrated by manifold experiments carried out at Rice Research Centre, just nearby the study area, water management options on temperate rice-fields differently affect the environment as a whole, in terms of water pollution, heavy metals concentration and greenhouse gasses emissions. Especially in dry seeded cropping systems, nitrates represent strong concerns for the quality of surface and ground water [45], Cadmium concentration in rice grain has turned out to be higher than the standard limit [59]. All these elements are to be properly taken into account when analyzing the environmental advantages of different irrigation practices, as well as when environmental cost of water resource needs to be quantified.

\section{Conclusions}

The approach presented serves as a contribution for the discussion about the efficient and sustainable use of water resource in agriculture. Along with innovative water management modalities, 
the adoption of ameliorated crop varieties was considered in this study as possible solution to address the topic.

In deepening the optimal allocation of resources in irrigated agriculture, few studies takes simultaneously into account both economic and environmental concerns; even less are those focusing on agriculture in temperate areas. The model implemented tries to fill this gap, with particular attention to a sector, i.e., rice-cultivation, which is particularly distinctive of the Po Valley, important for the regional economy and representative of a water-consuming activity that has been suffering from reduced resource availability.

Despite the homogeneous area used as reference, the lack of detailed information about soil characteristics makes the model not properly spatially-dependent. Rather, indeed it is limited to suggest the optimal management of rice-growing area, and indirectly the allocation of irrigation water. Therefore, further research is to be put into the characteristics of the region, as well as into the interaction between agricultural activity and the environment as a whole. The approach adopted required to extremely simplify the representation of the regional system, while all the economic and environmental implications at district level should be accounted for before putting into practice the land use conversion suggested by the optimization model. In addition, it was developed starting from results of field-level experiments and the actual suitability of scaling them up at regional level is a further concern to be properly investigated.

It is then necessary to overcome the purely deterministic nature of the model, which only suggests a set of options not always practically feasible. On the other hand, the need emerges to identify adequate tools for estimating the environmental value of paddy fields, given the manifold interactions between water management and the environment, and their effects.

Acknowledgments: The study was supported by the BIOGESTECA project ("Piattaforma di biotecnologie verdi e di tecniche gestionali per un sistema agricolo ad elevate sostenibilità ambientale") funded by Regione Lombardia, POLORISO project ("Ricerca, sperimentazione, tecnologie innovative, sostenibilità ambientale ed alta formazione per il potenziamento della filiera risicola nazionale") funded by Ministero delle Politiche Agricole, Alimentari e Forestali (MiPAAF) and GS-RUSE project ("Genomic selection for resources use efficiency in rice") founded by Agropolis Fondation and Fondazione Cariplo.

Author Contributions: Federica Monaco and Guido Sali conceived the study, developed the methodological approach and formulated the model; Federica Monaco wrote the paper; Guido Sali coordinator contributed to the writing; Manel Ben Hassen performed field experiments and analysis concerning innovative cultivars and contributed to the writing; Arianna Facchi; Marco Romani and their respective staffs conceived and performed field experiments at Rice Research Centre; Giampiero Valè coordinated experiments carried out at CREA site in in Vercelli concerning the selection of innovative cultivars. All the authors read and approved the final version of the paper.

Conflicts of Interest: The authors declare no conflict of interest.

\section{Abbreviations}

The following abbreviations are used in this manuscript:

$\begin{array}{ll}\text { APAT } & \begin{array}{l}\text { Agenzia per la Protezione dell'Ambiente e per i servizi Tecnici } \\ \text { (i.e., Italian Environment Protection Agency) }\end{array} \\ \text { CAP } & \text { Common Agricultural Policy } \\ \text { CREA } & \text { Council for Agricultural Research and Economics } \\ \text { MCA } & \text { Multi Criteria Analysis } \\ \text { WUA } & \text { Water User Association } \\ \text { UAA } & \text { Utilisable Agricultural Area } \\ \text { FLD } & \text { Water seeded rice and continuous flooding } \\ \text { DFL } & \text { Dry-seeded rice and delayed flooding } \\ \text { IRR } & \text { Dry-seeded rice and intermittent irrigation } \\ \text { WS } & \text { Water Saved } \\ \text { GM } & \text { Gross Margin } \\ \text { NI } & \text { Net Irrigation }\end{array}$




\section{References}

1. Ente Nazionale Risi. XLVIII Relazione Annuale. Anno 2015. Rice Research Centre, Castello d'Agogna (PV), Italy. Available online: http://www.enterisi.it/upload/enterisi/documentiallegati/Relaz.Risi2015DEF_ 13660_594.pdf (accessed on 5 August 2016).

2. Ferrero, A. Rice scenario in the European Union. Cah. Agric. 2007, 16, 272-277.

3. Fischler, G.; Tubiello, F.N.; van Velthuizen, H.; Wiberg, D.A. Climate change impacts on irrigation water requirements: Effects of mitigation, 1990-2080. Technol. Forecast Soc. 2007, 74, 1083-1107. [CrossRef]

4. Giorgi, F.; Lionello, P. Climate change projections for the Mediterranean region. Glob. Planet Chang. 2008, 63, 90-104. [CrossRef]

5. Mancosu, N.; Snyder, R.L.; Kyriakakis, G.; Spano, D. Water scarcity and future challenges for food production. Water 2015, 7, 975-992. [CrossRef]

6. Garrote, L.; Iglesias, A.; Granados, A.; Mediero, L.; Martin-Carrasco, F. Quantitative assessment of climate change vulnerability of irrigation demands in Mediterranean Europe. Water Resour. Manag. 2015, 29, 325-338. [CrossRef]

7. Bouman, B.A.M.; Lampayan, R.M.; Tuong, T.P. Water Management in Irrigated Rice; Coping with Water Scarcity; International Rice Research Institute: Los Banos, Philippines, 2007.

8. Strosser, P.; Dworak, T.; Garzon Delvaux, P.A.; Berglund, M.; Schmidt, G.; Mysiak, J.; Kossida, M.; Iacovides, I.; Ashton, V. Gap Analysis of the Water Scarcity and Droughts Policy in the EU. European Commission Tender ENV.d.1/SER/2010/0049. 2012. Available online: http://ec.europa.eu/environment/water/quantity/pdf/ WSDGapAnalysis.pdf (accessed on 5 August 2016).

9. Coppola, E.; Verdecchia, M.; Giorgi, F.; Colaiuda, V.; Tomassetti, B.; Lombardi, A. Changing hydrological conditions in the Po basin under global warming. Sci. Total Environ. 2014, 493, 1183-1196. [CrossRef] [PubMed]

10. Bischetti, G.B.; Chiaradia, E.A.; Gandolfi, C.; Monaco, F.; Sali, G. Irrigation water resource: Economic evaluation and scenario analysis in a rice-cultivated area. In Economics of Water Management in Agriculture; Bournaris, T., Berbel, J., Manos, B., Viaggi, D., Eds.; CRC Press: Boca Raton, FL, USA, 2014; pp. 98-125.

11. Elliot, J.; Deryng, D.; Müller, C.; Frieler, K.; Konzmann, M.; Dieter Gerten, D.; Glotter, M.; Flörke, M.; Wada, Y.; Best, N.; et al. Constraints and potentials of future irrigation water availability on agricultural production under climate change. Proc. Natl. Acad. Sci. USA 2014, 111, 3239-3244. [CrossRef] [PubMed]

12. García de Jalón, S.; Iglesias, A.; Cunningham, R.; Pérez Díaz, J.I. Building resilience to water scarcity in southern Spain: A case study of rice farming in Doñana protected wetlands. Reg. Environ. Chang. 2014, 14, 1229-1242. [CrossRef]

13. Maeda, S.; Nagamochi, T.; Kawachu, T.; Takeuchi, J. Regional allocation of irrigation water in a rice paddy area with water-saving practices. Irrig. Drain. Syst. 2011, 25, 81-96. [CrossRef]

14. Blanco-Gutierrez, I.; Varela-Ortega, C.; Purkey, D.R. Integrated assessment of policy interventions for promoting sustainable irrigation in semi-arid environments: A hydro-economic modeling approach. J. Environ. Manag. 2013, 128, 144-160. [CrossRef] [PubMed]

15. Ferrero, A.; Nguyen, N.V. The sustainable development of rice-based production systems in Europe. In Proceedings of the FAO Rice Conference, Rome, Italy, 12-13 February 2004; Available online: http: //www.fao.org/3/a-y5682e.pdf (accessed on 5 August 2016).

16. Cortignani, R.; Dono, G.; Doro, L.; Ledda, L.; Mazzapicchio, G. Una valutazione dell'impatto economico dei cambiamenti climatici tramite un modello di programmazione stocastica discrete a 3 stadi. In Proceedings of the Comunicazione al XLVII Convegno di Studi SIDEA, Campobasso, Italy, 22-25 September 2010.

17. Dono, G.; Giraldo, L.; Severini, S. Pricing of irrigation water under alternative charging methods: Possible shortcomings of a volumetric approach. Agric. Water Manag. 2010, 97, 1785-1805. [CrossRef]

18. Dono, G.; Marongiu, S.; Severini, S.; Sistu, G.; Strazzera, E. Studio Sulla Gestione Sostenibile delle Risorse Idriche: Analisi dei Modelli di Consumo per usi Irrigui e Civili; DRES, Università degli Studi di Cagliari-ENEA-DEAR, Università degli Studi della Tuscia: Viterbo, Italy, 2007.

19. Rodrigues, G.C.; Paredes, P.; Gonçalves, J.M.; Alves, I.; Pereira, L.S. Comparing sprinkler and drip irrigation systems for full and deficit irrigated maize using multicriteria analysis and simulation modelling: Ranking for water saving vs. farm economic returns. Agric. Water Manag. 2013, 126, 85-96. [CrossRef] 
20. Clément, G.; Louvel, D. Amélioration variétale du riz pour la France méditerranéenne. Cah. Agric. 2013, 22, 459-465.

21. Tesio, F.; Tabacchi, M.; Cerioli, S.; Follis, F. Sustainable hybrid rice cultivation in Italy: A review. Agron. Sustain. Dev. 2014, 34, 93-102. [CrossRef]

22. Tuong, T.P. Technologies for efficient utilization of water in rice production. In Proceedings of the Advances in Rice Science of the International Rice Science Conference, Seoul, Korea, 13-15 September 2010; Lee, K.S., Jena, K.K., Heong, K.L., Eds.; Rural Development Administration: Suwon, Korea, 2005; pp. 141-161.

23. López-Piñeiro, A.; Sanchez-llerena, J.; Pena, D.; Albarran, A. Transition from flooding to sprinkler irrigation in Mediterranean rice growing ecosystems: Effect on behaviour of bispyribac sodium. Agric Ecosyst Environ. 2016, 223, 99-107. [CrossRef]

24. He, C. Effects of furrow irrigation on the growth, production and water use efficiency of direct sown rice. Sci. World J. 2010, 10, 1483-1497. [CrossRef] [PubMed]

25. Cesari de Maria, S.; Rienzner, M.; Facchi, A.; Chiaradia, E.A.; Romani, M.; Gandolfi, C. Water balance implications of switching from continuous submergence to flush irrigation in a rice-growing district. Agric. Water Manag. 2016, 171, 108-119. [CrossRef]

26. Sali, G.; Monaco, F. Irrigation water resource in a rice-growing area: Economic evaluation under different pricing conditions. In Agricultural Cooperative Management and Policy. New Robust, Reliable and Coherent Modelling Tools; Zopounidis, C., Kalogeras, N., Mattas, K., van Dij, G., Baourakis, G., Eds.; Springer International Publishing Switzerland: Cham, Switzerland, 2014; pp. 23-40.

27. Nie, L.; Peng, S.; Chen, M.; Shah, F.; Huang, J.; Cui, K.; Xiang, J. Aerobic rice for water-saving in agriculture. A review. Agron. Sustain. Dev. 2012, 32, 411-418. [CrossRef]

28. Dunn, E.W.; Gaydon, D.S. Rice growth: Yield and water productivity responses to irrigation scheduling prior to the delayed application to continuous flooding in south-east Australia. Agric. Water Manag. 2011, 98, 1799-1807. [CrossRef]

29. BIOGESTECA. Quaderno Gestione Della Risorsa Irrigua, Biogesteca Project Founded by Regione Lombardia. Regione Lombardia, Italy, 2014. Available online: http://www.biogesteca.unimi.it/Gestione\%20della\% 20risorsa\%20irrigua.pdf (accessed on 5 August 2016).

30. De Vries, M.E.; Rodenburg, J.; Bado, B.V.; Sow, A.; Leffelaar, P.A.; Giller, K.E. Rice production with less irrigation water is possible in a Sahelian environment. Field Crop Res. 2010, 116, 154-164. [CrossRef]

31. Darouich, H.M.; Pedras, C.M.G.; Gonçalves, J.M. Drip vs. surface irrigation: A comparison focussing on water saving and economic returns using multicriteria analysis applied to cotton. Biosyst. Eng. 2014, 122, 74-90. [CrossRef]

32. Darouich, H.; Gonçalves, J.M.; Muga, A.; Pereira, J.L. Water saving vs. farm economics in cotton surface irrigation: An application of multicriteria analysis. Agric. Water Manag. 2012, 115, 223-231. [CrossRef]

33. Groot, J.C.J.; Oomen, G.J.M.; Rossing, W.A.H. Multi-objective optimization and design of farming systems. Agric. Syst. 2012, 110, 63-77. [CrossRef]

34. Latinopoulos, D. Multicriteria decision-making for efficient water and land resources allocation in irrigated agriculture. Environ. Dev. Sustain. 2009, 11, 329-343. [CrossRef]

35. Zhang, Q.; Maeda, S.; Kawachi, T. Stochastic multiobjective optimization model for allocating irrigation water to paddy fields. Paddy Water Environ. 2007, 5, 93-99. [CrossRef]

36. Bartolini, F.; Bazzani, G.M.; Gallerani, V.; Raggi, M.; Viaggi, D. The impact of water and agriculture policy scenarios on irrigated farming systems in Italy: An analysis based on farm level multi-attribute linear programming models. Agric. Syst. 2007, 93, 90-114. [CrossRef]

37. Graveline, N. Economic calibrated models for water allocation in agricultural production: A review. Environ. Model. Softw. 2016, 81, 12-25. [CrossRef]

38. Berbel, J.; Rodriguez-Ocaña, A. MCDM approach to production analysis: An application to irrigated farms in Southern Spain. Eur. J. Oper. Res. 1998, 107, 108-118. [CrossRef]

39. Ente Nazionale Risi. Database Delle Superfici Coltivate-Superfici Coltivate. Available online: http:/ /www. enterisi.it/servizi/seriestoriche/superfici_fase01.aspx (accessed on 5 August 2016).

40. Massarutto, A. Water pricing and irrigation water demand. Economic efficiency versus environmental sustainability. Eur. Environ. 2003, 13, 100-119. [CrossRef]

41. Sistema Informativo Agricolo della Regione Lombardia (SIARL). Available online: https://www.siarl. regione.lombardia.it/index.htm (accessed on 5 August 2016). 
42. DUSAF 2012. Banca Dati Della Destinazione d'Uso dei Suoli Agricoli e Forestali. Available online: http: //www.cartografia.regione.lombardia.it/rlregisdownload/ (accessed on 5 August 2016).

43. Lilienfeld, A.; Asmild, M. Estimation of the excess water use in irrigated agriculture. A data envelopment analysis approach. Agric. Water Manag. 2007, 94, 73-82. [CrossRef]

44. Chiaradia, E.A.; Facchi, A.; Masseroni, D.; Ferrari, D.; Bischetti, G.B.; Gharsallah, O.; Cesari de Maria, S.; Rienzner, M.; Naldi, E.; Romani, M.; et al. An integrated multisensor system for the continuous monitoring of water dynamics in rice fields under different irrigation regimes. Environ. Monit. Assess. 2015, 187, 586-603. [CrossRef] [PubMed]

45. Miniotti, E.F.; Romani, M.; Said-Pullicino, D.; Facchi, A.; Bertora, C.; Peyron, M.; Sacco, D.; Bischetti, G.B.; Lerda, C.; Tenni, D.; et al. Agro-environmental sustainability of different water management practices in temperate rice agro-ecosystems. Agric. Ecosyst. Environ. 2016, 222, 235-248. [CrossRef]

46. Watanabe, T. Water budget in paddy fields lots. In Proceedings of the International Workshop on Soil Water Engineering for Paddy Field Management, Bangkok, Thailand, 28-30 January 1992; Muty, V.V.N., Koga, K., Eds.; Asian Institute of Technology: Bangkok, Thailand, 1992; pp. 1-11.

47. GRANARIA, Quotazione dei Prezzi All'ingrosso Sulla Piazza di Milano. Available online: http://www. granariamilano.org/pagina.php?id_sottomenu=8\&id_menu=2 (accessed on 5 August 2016).

48. Borrell, A.; Garside, A.; Fulai, S. Improving efficiency of water use for irrigated rice in a semi-arid tropical environment. Field Crops Res. 1997, 52, 231-248. [CrossRef]

49. Camera di Commercio di Vercelli. Il Bilancio Economico Dell'azienda Risicola. Modello di Impostazione ed Esame di Quattro Casi Rappresentativi. Collana "I quaderni", n. 8, 2013. Available online: http: //images.vc.camcom.it/f/studiestatistica/46/4698_CCIAAVC_1022014.pdf (accessed on 5 August 2016).

50. Gioia, M. Riso, L'analisi dei Costi di Produzione. Available online: http://agronotizie.imagelinenetwork. com/agricoltura-economia-politica/2010/09/07/riso-1-analisi-dei-costi-di-produzione/9769 (accessed on 5 August 2016).

51. Regione Lombardia. Programma di Sviluppo Rurale 2007-2013. Allegato 6: Giustificazione Economica Dei Premi. Regione Lombardia, Italy, 2009. Available online: http:/ /www.provincia.pv.it/attachments/article/ 96/all_6-giustificazione_econimica_premi_rev12.09.pdf (accessed on 5 August 2016).

52. Castellani, L.; Mancuso, T.; Massaglia, S. Aspetti normative ed economici in materia di gestione e tutela delle risorse idriche ad uso irriguo in Piemonte. In Acqua, Agricoltura e Ambiente nei Nuovi Scenari di Politica Comunitaria; Casini, L., Gallerani, V., Viaggi, D., Eds.; Franco Angeli editore: Milano, Italy, 2007; pp. 31-48.

53. Romero, C.; Rehman, T. Multiple Criteria Analysis for Agricultural Decisions; Elsevier Science Publishers: Amsterdam, The Netherlands, 2003.

54. Hallaji, K.; Yazicigil, H. Optimal management of coastal aquifer in southern Turkey. J. Water Resour. Plan. Manag. 1996, 122, 233-244. [CrossRef]

55. Singh, A.; Panda, S.N.; Saxena, C.K.; Verma, C.L.; Uzokwe, V.N.E.; Krause, P.; Gupta, S.K. Optimization modelling for conjunctive use planning of surface water and groundwater for irrigation. J. Irrig. Drain. Eng. 2015, 142. [CrossRef]

56. Ente Nazionale Risi. Database delle Superfici Coltivate-Ripartizione Aziendale. Available online: http: //www.enterisi.it/servizi/seriestoriche/ripartizione_fase01.aspx (accessed on 1 May 2012).

57. Cadario, D.; Bischetti, G.B. Caratteri e Funzioni del Reticolo Idrografico Della Pianura Lombarda. Valutazione Ambient. 2006, 10, 58-61.

58. Said-Pullicino, D.; Miniotti, E.F.; Sodano, M.; Bertora, C.; Lerda, C.; Chiaradia, E.A.; Romani, M.; Cesari de Maria, S.; Sacco, D.; Celi, L. Linking dissolved organic carbon cycling to organic carbon fluxes in rice paddies under different water management practices. Plant Soil 2015. [CrossRef]

59. Cattani, I.; Romani, M.; Boccelli, R. Effect of cultivation practices on cadmium concentration in rice grain. Agron. Sustain. Dev. 2008, 28, 265-271. [CrossRef]

(C) 2016 by the authors; licensee MDPI, Basel, Switzerland. This article is an open access article distributed under the terms and conditions of the Creative Commons Attribution (CC-BY) license (http://creativecommons.org/licenses/by/4.0/). 